\title{
Age-Related Biomarkers Can Be Modulated by Diet in the Rat ${ }^{*}$
}

\author{
Hilary Anne MacQueen ${ }^{1}$, Wassif Samuel Wassif ${ }^{2}$, Ian Walker ${ }^{2}$, Dawn Angela Sadler ${ }^{3}$, Karen Evans ${ }^{1}$ \\ ${ }^{1}$ Department of Life Sciences, The Open University, Walton Hall, Milton Keynes, UK; ${ }^{2}$ Department of Clinical Chemistry, Bedford \\ Hospital, Bedford, UK; ${ }^{3}$ Intervet Ltd., Walton Manor, Milton Keynes, UK. \\ Email: h.a.macqueen@open.ac.uk
}

Received July $6^{\text {th }}, 2011$; revised August 17 th $^{\text {th } 2011 \text {; accepted August 24 }}$, 2011.

\begin{abstract}
This study seeks to establish the normal serum concentrations of biochemical markers related to nutrition, inflammation and disease, and to investigate how the levels change with age and diet in the rat. To this end, we fed rats from weaning on three diets differing in their protein, carbohydrate and fatty acid content. The diets consisted of a control, nutritionally balanced diet, this same diet supplemented with $10 \%(\mathrm{wt} / \mathrm{wt})$ beef tallow, and a diet that was high in fat and carbohydrate and low in protein. Blood samples from rats at two different ages, 3 months and 12 months, were then analysed. In control rats, with advancing age there was a general decrease in potassium, iron and serum albumin concentrations and in the activities of aspartate aminotransferase and alanine aminotransferase, and an increase in total and $H D L$ cholesterol. These changes were modulated by diet: many of the age-related changes (serum concentrations of potassium, iron and cholesterol, and liver enzyme activities) were not observed in animals eating the high fat diet. In contrast, the high carbohydrate, high fat, low protein diet-fed animals showed several additional changes (serum concentrations of sodium, urea, creatinine and TG, and activity of alkaline phosphatase) that can be related to kidney, liver and cardiovascular health.
\end{abstract}

Keywords: Ageing, Disease, Diet, Biomarker, Rat

\section{Introduction}

Ageing is a complex process, involving gradual changes in the functioning of many body systems, and ultimately leading to irreversible loss of viability. There is considerable interest in identifying causative mechanisms involved in ageing, with a view to finding interventions that will reverse if not all, then at least the most debilitating losses of function, thereby maximising quality of life. It is relatively straightforward to identify failing processes in elderly animals and humans; much less evident are early changes marking the onset of such failures before clinical signs become apparent [1]. Here we have used a rat model to identify such early changes by studying parameters associated with particular clinical conditions in animals of two ages. We have investigated whether, in line with previous suggestions [2], the parameters can be affected by diet and might therefore be amenable to modulation by dietary components, leading to therapeutic benefit.

*This work was supported by The Open University.
Besides a generalised loss of function in many body systems, ageing is frequently accompanied by the development of a pro-inflammatory state in which circulating levels of pro-inflammatory cytokines, particularly IL-6, are elevated [3]. This state has been referred to as inflammaging [4]. Prolonged inflammation has been associated with several debilitating conditions such as inflammatory bowel disease, rheumatoid arthritis, neurodegenerative diseases and cardiovascular disease $[5,6]$.

We and others have previously shown that immune responses, including inflammation, can be modulated by diet [7-10]. Moreover there is a large body of literature relating to the effects of diet on various parameters of health, particularly cardiovascular disease [11]. Our hypothesis is that the biomarkers shown in this study to change with age can be modulated by different diets.

To investigate changes in diagnostic parameters over time we used rats aged 3 months (young adults) and 12 months (middle-aged). The rats were fed one of three diets from weaning: a nutritionally balanced rat maintenance diet, this same diet supplemented with $10 \% \mathrm{wt} / \mathrm{wt}$ tallow, or a diet high in carbohydrate and fat and low in 
protein. Blood samples were taken from the rats and tested for biochemical indicators of metabolic health (sodium, potassium, iron, transferrin, ferritin), for indicators of kidney (urea, creatinine) and liver (albumin, bilirubin, alkaline phosphatase (AP), aspartate aminotransferase (AST), alanine aminotransferase (ALT), $\gamma$-glutamyl transferase (GGT)) function, for lipid profile (total cholesterol, triacylglycerols (TG), high density lipoprotein (HDL)cholesterol, low density lipoprotein (LDL)-cholesterol) and, since chronic inflammation is a marker of ageing [12], for indicators of immune responses (C-reactive peptide (CRP), IL-1 $\beta$, IL-6, IL-10, IFN $\gamma$ and TNF $\alpha$ ).

\section{Experimental Methods}

\subsection{Animals}

Animals were male Sprague-Dawley rats, bred in-house and maintained in an enriched environment on a $14 \mathrm{~h}$ light: $10 \mathrm{~h}$ dark cycle. Animals were kept and treated in accordance with the UK Animals (Scientific Procedures) Act, 1986, and the experiments were approved by the Open University Animal Ethics Advisory Group. Rats were weaned at three weeks of age directly onto the experimental or control diets which were available ad lib, and were maintained at three littermates per cage until the age of 12 - 14 weeks or 12 months, when they were used. During this period each rat was weighed once or twice a week, and examined visually for signs of ill-health. Rats were given an Aspen Block (Lillico, UK) to gnaw, and no dental problems were experienced. The growth curves of the three groups of rats are shown in Figure 1. No significant differences were seen between them.

\subsection{Diets}

Components of the diets, previously described [13], are shown in Table 1. Briefly, the control diet was RM3 (Special Diet Services, Witham, Essex, UK). One experimental diet (high fat, HF) was RM3 supplemented with $10 \%$ $\mathrm{wt} / \mathrm{wt}$ beef tallow (Atora, UK), and was rich in saturated fats. The second experimental diet (HFHS) was based on chocolate cake mix supplemented with vitamins, minerals, carrots and eggs; this diet was high in fat (especially saturated fats) and sugars, and low in protein. The diets were made up twice per week, and gas-liquid chromatographic analysis of the diets over a week confirmed that the fatty acid profiles did not deteriorate substantially over the first four days of storage (data not shown).

\subsection{Blood Sampling}

At the time of harvest, rats were deeply anaesthetised with Isofane (Novartis Animal Health UK Ltd). Approximately 4 $\mathrm{ml}$ of blood was obtained by cardiac puncture. Following coagulation at room temperature the clots were spun down and the supernatants were removed and stored at $-80^{\circ} \mathrm{C}$

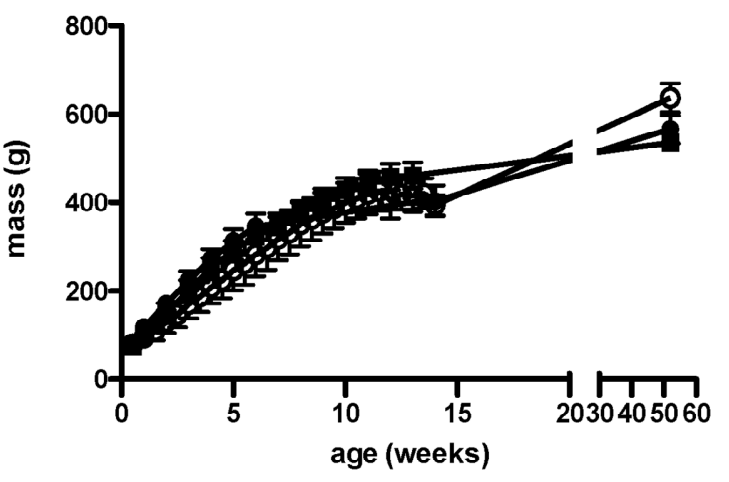

Figure 1. Growth curves for rats eating each of the three diets. Squares $=$ control; open circles $=$ HFHS; closed circles $=$ HF .

Table 1. Experimental diets used in this study.

\begin{tabular}{lccc}
\hline \multicolumn{1}{c}{ Constituent } & \multicolumn{3}{c}{ Diet } \\
\hline & Control & High fat & HFHS \\
\hline Energy kJ/100g & 1530 & 1699 & 1513 \\
Protein g/100g & 22.3 & 20.4 & 7.3 \\
Protein: energy & 14.6 & 12 & 4.8 \\
Carbohydrate g/100g & 43.5 & 40.4 & 38.9 \\
Sugars & 7.7 & 7.0 & 22.7 \\
Fat g/100g & 4.3 & 11.8 & 9.8 \\
SFA & 0.7 & 4.9 & 3.1 \\
MUFA & 1.24 & 3.8 & 2.9 \\
PUFA & 1.74 & 1.69 & 2.5 \\
U:S & 4.26 & 1.12 & 1.74 \\
Fibre g/100g & 12.2 & 11.1 & 1.6 \\
Vitamins and minerals g/100g & 2.5 & 2.3 & 2.8 \\
\hline
\end{tabular}

until analysis. Following cardiac bleeding, the rats were killed by intracardiac injection of Pentoject (Animal Care Ltd, UK).

\subsection{Biochemical Analyses}

Serum metabolites, electrolytes, renal profile, liver function and lipid profile were analysed using a Cobas Integra 800 analyser (Roche Diagnostics, Mannheim, Germany). Nine animals under each condition were tested for every analyte. Sera from the same animals were also used in triplicate in ELISAs to determine circulating levels of IL-1 $\beta$, IL-6, IL-10, IFN $\gamma$ and TNF $\alpha$. All ELISA assays were carried out using kits purchased from R\&D Systems Ltd, Abingdon, UK.

Analytes and their clinical relevance are shown in Table 2. 


\subsection{Statistical Analyses}

Since the rats were kept at three per cage, and nine individuals were used for each treatment (three cages), the experimental unit was three for each of four treatments (three diets and one age difference). According to Mead's resource equation [14], this gives an E value of 14, meaning that the numbers of animals used are appropriate to give robust data. All data are expressed as mean \pm SEM. Differences between means were assessed by ANOVAs and t-tests as appropriate, using Prism v5 (GraphPad Software, San Diego, California, USA, www.graphpad.com). ANOVAs were validated by using Bartlett's test for equality of variances. Differences were considered statistically significant at the $P<0.05$ level.

\section{Results}

\subsection{Individual Differences}

ANOVA confirmed that there were no significant differences in the analyte patterns between individuals in the same treatment cohort (data not shown).

Levels of analytes were compared between three month and 12-month animals eating each diet. The results are shown in Tables 3-7. Changes with age in animals eating a normal diet are shown in columns 2 and 3 in all these Tables. The effects of diet can be seen in columns 5 and 6 for the HF diet, and columns 8 and 9 for the HFHS diet.

\subsection{Changes with Age}

Table 3 shows the normal pattern of change in electrolyte levels with age (columns 2 and 3). Sodium, transferrin and ferritin do not change over the time period studied; however potassium and iron levels fall with age.

Table 4 shows the values for markers of kidney function. There are no significant changes over this time period in animals eating a control diet.

Table 5 shows the values for markers of liver function. There are no changes in bilirubin, alkaline phosphatase or GGT values; however AST and ALT both show significantly decreased activity over the time period studied.

Table 6 shows the values of blood lipid levels. There is no significant change in LDL-cholesterol; however HDLcholesterol, and hence total cholesterol, values were signifycantly increased over this time period in control animals.

Table 7 shows the values for markers of immune function, used as proxies for inflammaging. No differences were seen either with age or diet in these animals.

\subsection{Baseline Values in Animals Eating Experimental Diets}

Considering the HF diet, baseline values were similar to the control diet values for all the analytes except for the concentration of serum potassium and the activities of AST and ALT, which were lower in animals eating the experimental diet, and the concentrations of sodium and $\mathrm{TG}$, and the activity of alkaline phosphatase, which were higher with the experimental diet (Tables 3, 5 and 6). Baseline values of all types of serum cholesterol were unchanged (Table 6).

Considering the HFHS diet, baseline serum concentrations of potassium, iron and urea, and the activities of AST and ALT were lower than with the control diet, while the concentrations of sodium, LDL cholesterol and $\mathrm{TG}$, and the activity of alkaline phosphatase were higher (Tables 3-6). Other analytes showed values similar to those found in animals eating the control diet.

\subsection{Changes with Age in Animals Eating the Experimental Diets}

In animals eating the HF diet, only one analyte showed a significant change that was not observed in control animals: the activity of alkaline phosphatase decreased between the ages of 3 and 12 months. The decreases observed in control animals in the concentration of albumin and in the AST: ALT ratio were also seen in the HF animals, but none of the other changes seen in control animals were reproduced in animals eating this diet.

In animals eating the HFHS diet there were a number of similarities with values obtained from animals eating the control diet, in particular the decrease observed in the serum concentration of potassium and the increase in total and HDL-cholesterol. A number of differences were also observed: there was a decrease in the activity of alkaline phosphatase similar to that observed in the HF rats, and there were increases in the concentrations of serum sodium, urea and creatinine that were not observed in animals eating either of the other diets. However, in contrast to the decrease seen in control animals, there was an increase in the activity of AST and the AST: ALT ratio. There was also an increase in the serum TG concentration.

These changes are summarised in Table 8, which shows the analytes that were altered over time in animals eating the control diet, and the direction and extent of the changes in these analytes exhibited by ageing animals eating the experimental diets.

\section{Discussion}

Our results indicate that there are substantial age-related changes in metabolism in animals fed a nutritionally well-balanced diet (Tables 3-8) that can be detected through blood analysis at a relatively young age. We detected changes in markers of liver function and cardiovascular risk factors, but no changes in markers of kidney or immune function. However, in animals eating 
Table 2. Analytes investigated in this study and their clinical significance.

\begin{tabular}{lllll}
\hline Metabolic profile & Kidney function & Liver function & Lipid profile & Immune status \\
\hline Sodium & Urea & Albumin & Total cholesterol & CRP \\
Potassium & Creatinine & Bilirubin & HDL-cholesterol & IL-1 $\beta$ \\
Iron & & AP & LDL-cholesterol & IL-6 \\
Transferrin & & TG & IL-10 \\
Ferritin & & AST & IFN $\gamma$ \\
& & ALT & TNF $\alpha$ & \\
\hline
\end{tabular}

Table 3. Levels of analytes denoting general metabolic condition in rats of two ages eating one of three diets. ${ }^{1}$

\begin{tabular}{|c|c|c|c|c|c|c|c|c|c|}
\hline & & & & & Diet & & & & \\
\hline Analyte / unit & $\begin{array}{c}\text { Control } 3 \\
\text { month }\end{array}$ & $\begin{array}{l}\text { Control } 12 \\
\text { month }\end{array}$ & Change & $\begin{array}{l}\text { High fat } 3 \\
\text { month }\end{array}$ & $\begin{array}{l}\text { High fat } 12 \\
\text { month }\end{array}$ & Change & $\begin{array}{c}\text { HFHS } 3 \\
\text { month }\end{array}$ & $\begin{array}{l}\text { HFHS } 12 \\
\text { month }\end{array}$ & Change \\
\hline $\begin{array}{l}\text { Sodium / } \\
\text { mmol. } 1^{-1}\end{array}$ & $111.0 \pm 9.02$ & $134.0 \pm 5.89$ & n.s. & $132.3 \pm 4.62$ & $134.1 \pm 1.65$ & n.s. & $130.3 \pm 2.13$ & $146.2 \pm 0.83$ & $\operatorname{Inc} * * *$ \\
\hline $\begin{array}{l}\text { Potassium / } \\
\mathrm{mmol}^{\prime} \cdot \mathrm{l}^{-1}\end{array}$ & $35.13 \pm 2.75$ & $14.2 \pm 0.9$ & Dec** & $13.9 \pm 1.25$ & $15.23 \pm 0.34$ & n.s. & $10.77 \pm 0.13$ & $5.87 \pm 0.12$ & Dec*** \\
\hline Iron $/ \mathrm{mmol} \cdot 1^{-1}$ & $44.67 \pm 1.86$ & $27.33 \pm 1.33$ & $\operatorname{Dec}^{* *}$ & $50.33 \pm 2.9$ & $37.67 \pm 2.85$ & n.s. & $26.0 \pm 1.53$ & $31.3 \pm 3.8$ & n.s. \\
\hline $\begin{array}{c}\text { Transferrin/ } \\
\mathrm{mmol}^{-1} \mathrm{l}^{-1}\end{array}$ & ND & $0.89 \pm 0.1$ & n.s. & ND & ND & n.s. & ND & ND & n.s. \\
\hline Ferritin $/ \mu \mathrm{g} \cdot 1^{-1}$ & ND & ND & n.s. & ND & ND & n.s. & ND & ND & n.s. \\
\hline
\end{tabular}

${ }^{1}$ Data are means \pm SEM. The direction of change is indicated: Inc $=$ increase, Dec $=$ decrease; ND = not detectable; asterisks show within-diet significance at the $* * P<0.01$ and $* * * P<0.001$ levels; n.s., no significant change.

Table 4. Markers of kidney function in rats of two ages eating one of three diets. ${ }^{1}$

\begin{tabular}{|c|c|c|c|c|c|c|c|c|c|}
\hline & \multicolumn{9}{|c|}{ Diet } \\
\hline Analyte/unit & $\begin{array}{c}\text { Control } 3 \\
\text { month }\end{array}$ & $\begin{array}{c}\text { Control } 12 \\
\text { month }\end{array}$ & Change & $\begin{array}{l}\text { High fat } 3 \\
\text { month }\end{array}$ & $\begin{array}{l}\text { High fat } 12 \\
\text { month }\end{array}$ & Change & $\begin{array}{c}\text { HFHS } 3 \\
\text { month }\end{array}$ & $\begin{array}{c}\text { HFHS } 12 \\
\text { month }\end{array}$ & Change \\
\hline Urea $/ \mathrm{mmol} \cdot \mathrm{l}^{-1}$ & $7.67 \pm 0.74$ & $7.84 \pm 0.39$ & n.s. & $6.85 \pm 0.65$ & $6.92 \pm 0.23$ & n.s. & $3.26 \pm 0.19$ & $4.31 \pm 0.26$ & Inc** \\
\hline $\begin{array}{c}\text { Creatinine/ } \\
\mathrm{mmol}^{-1} \mathrm{l}^{-1}\end{array}$ & $37.0 \pm 14.1$ & $37.7 \pm 5.04$ & n.s. & $33.3 \pm 5.78$ & $25.3 \pm 0.67$ & n.s. & $31.67 \pm 1.2$ & $50.33 \pm 2.4$ & $\operatorname{Inc} * *$ \\
\hline
\end{tabular}

${ }^{1}$ Data are means \pm SEM. The direction of change is indicated: $I n c=$ increase; asterisks show within-diet significance at the $* * P<0.01$ level; n.s., no significant change.

Table 5. Measured levels of liver function in rats of two ages eating one of three diets. ${ }^{1}$

\begin{tabular}{|c|c|c|c|c|c|c|c|c|c|}
\hline Analyte/unit & $\begin{array}{c}\text { Control } 3 \\
\text { month }\end{array}$ & $\begin{array}{c}\text { Control } 12 \\
\text { month }\end{array}$ & Change & $\begin{array}{l}\text { High fat } 3 \\
\text { month }\end{array}$ & $\begin{array}{l}\text { High fat } 12 \\
\text { month }\end{array}$ & Change & $\begin{array}{c}\text { HFHS } 3 \\
\text { month }\end{array}$ & $\begin{array}{l}\text { HFHS } 12 \\
\text { month }\end{array}$ & Change \\
\hline Albumin $/ \mu \mathrm{g} \cdot 1^{-1}$ & $33.67 \pm 2.03$ & $27.78 \pm 1.06$ & Dec* & $37.67 \pm 1.49$ & $33.0 \pm 1.27$ & Dec* & $37.67 \pm 1.38$ & $38.89 \pm 0.77$ & n.s. \\
\hline Bilirubin $/ \mu \mathrm{mol} \cdot 1^{-1}$ & $2.0 \pm 0$ & $1.0 \pm 0$ & n.s. & $1.33 \pm 0.17$ & $1.11 \pm 0.11$ & n.s. & $1.0 \pm 0$ & $1.56 \pm 0.18$ & n.s. \\
\hline $\mathrm{AP} / \mathrm{IU} \cdot 1^{-1}$ & $91.0 \pm 12.17$ & $104.33 \pm 9.4$ & n.s. & $198.3 \pm 22.5$ & $119.3 \pm 3.1$ & Dec* & $157.0 \pm 8.3$ & $103.3 \pm 10.4$ & Dec* \\
\hline $\mathrm{AST} / \mathrm{IU} \cdot 1^{-1}$ & $351.0 \pm 24.27$ & $108.7 \pm 21.88$ & Dec** & $210.0 \pm 32.1$ & $126.7 \pm 6.9$ & n.s. & $99.7 \pm 14.3$ & $228.7 \pm 10.3$ & Inc** \\
\hline $\mathrm{ALT} / \mathrm{IU} \cdot \mathrm{l}^{-1}$ & $117.3 \pm 3.71$ & $79.67 \pm 0.33$ & $\operatorname{Dec} * * *$ & $84.3 \pm 8.1$ & $105.7 \pm 6.3$ & n.s. & $46.0 \pm 7.6$ & $38.0 \pm 6.2$ & n.s. \\
\hline AST:ALT & $2.99 \pm 0.17$ & $1.36 \pm 0.27$ & Dec** & $2.52 \pm 0.46$ & $1.2 \pm 0.01$ & Dec* & $3.32 \pm 0.6$ & $6.26 \pm 0.74$ & Inc* \\
\hline $\mathrm{GGT} / \mathrm{IU} \cdot 1^{-1}$ & $1.0 \pm 0$ & $0.89 \pm 0.11$ & n.s. & $1.0 \pm 0$ & $1.0 \pm 0$ & n.s. & $1.0 \pm 0$ & $1.0 \pm 0$ & n.s. \\
\hline
\end{tabular}

${ }^{1}$ Data are means \pm SEM. The direction of change is indicated: Inc $=$ increase, Dec $=$ decrease; asterisks show within-diet significance at the $* P<0.05, * * P<$ 0.01 and $* * * P<0.001$ levels; n.s., no significant change. 
Table 6. Levels of blood lipid markers of cardiovascular risk in rats of two ages eating one of three diets. ${ }^{1}$

\begin{tabular}{|c|c|c|c|c|c|c|c|c|c|}
\hline & \multicolumn{9}{|c|}{ Diet } \\
\hline Analyte/unit & $\begin{array}{l}\text { Control } 3 \\
\text { month }\end{array}$ & $\begin{array}{l}\text { Control } 12 \\
\text { month }\end{array}$ & Change & $\begin{array}{l}\text { High fat } 3 \\
\text { month }\end{array}$ & $\begin{array}{l}\text { High fat } 12 \\
\text { month }\end{array}$ & Change & $\begin{array}{c}\text { HFHS } 3 \\
\text { month }\end{array}$ & $\begin{array}{c}\text { HFHS } 12 \\
\text { month }\end{array}$ & Change \\
\hline $\begin{array}{l}\text { Total cholesterol/ } \\
\mathrm{mmol} \cdot \mathrm{l}^{-1}\end{array}$ & $3.03 \pm 0.37$ & $7.03 \pm 1.18$ & Inc* & $3.4 \pm 0.45$ & $6.1 \pm 1.35$ & n.s. & $2.77 \pm 0.12$ & $3.93 \pm 0.39$ & Inc* \\
\hline $\begin{array}{l}\text { HDL-cholesterol/ } \\
\mathrm{mmol} \cdot \mathrm{l}^{-1}\end{array}$ & $2.2 \pm 0.27$ & $4.2 \pm 0.06$ & Inc** & $2.3 \pm 0.35$ & $3.43 \pm 0.29$ & n.s. & $1.37 \pm 0.07$ & $2.23 \pm 0.03$ & $\mathrm{Inc}^{* * *}$ \\
\hline $\begin{array}{l}\text { LDL-cholesterol/ } \\
\qquad \mathrm{mmol} \cdot \mathrm{l}^{-1}\end{array}$ & $0.4 \pm 0.11$ & $1.23 \pm 0.62$ & n.s. & $0.45 \pm 0.15$ & $1.53 \pm 0.64$ & n.s. & $0.73 \pm 0.03$ & $0.8 \pm 0.5$ & n.s. \\
\hline $\mathrm{TG} / \mathrm{mmol} \cdot \mathrm{l}^{-1}$ & $0.91 \pm 0.06$ & $3.52 \pm 1.59$ & n.s. & $2.52 \pm 1.13$ & $2.53 \pm 0.99$ & n.s. & $1.43 \pm 0.08$ & $2.74 \pm 0.15$ & Inc** \\
\hline
\end{tabular}

${ }^{1}$ Data are means \pm SEM. The direction of change is indicated: Inc $=$ increase; asterisks show within-diet significance at the $* P<0.05, * * P<0.01$ and $* * * P<$ 0.001 levels; n.s., no significant change.

Table 7. Levels of markers of inflammation in rats of two ages eating one of three diets. ${ }^{1}$

\begin{tabular}{cccccccccc}
\hline Analyte/unit & $\begin{array}{c}\text { Control } 3 \\
\text { month }\end{array}$ & $\begin{array}{c}\text { Control 12 } \\
\text { month }\end{array}$ & Change & $\begin{array}{c}\text { High fat } 3 \\
\text { month }\end{array}$ & $\begin{array}{c}\text { High fat } 12 \\
\text { month }\end{array}$ & Change & $\begin{array}{c}\text { HFHS } 3 \\
\text { month }\end{array}$ & $\begin{array}{c}\text { HFHS } 12 \\
\text { month }\end{array}$ & Change \\
\hline $\mathrm{CRP} / \mathrm{mg} \cdot \mathrm{l}^{-1}$ & $\mathrm{ND}$ & $\mathrm{ND}$ & n.s. & ND & ND & n.s. & ND & ND & n.s. \\
$\mathrm{IL}-1 / \beta / \mathrm{pg} \cdot \mathrm{ml}^{-1}$ & $149.9 \pm 0.59$ & $126.7 \pm 0.25$ & n.s. & $149.9 \pm 1.65$ & $121.7 \pm 0.73$ & n.s. & $174.9 \pm 6.12$ & $139.2 \pm 1.53$ & n.s. \\
$\mathrm{IL}-6 / \mathrm{pg} \cdot \mathrm{ml}^{-1}$ & $342.9 \pm 8.91$ & $314.3 \pm 1.26$ & n.s. & $316.5 \pm 2.85$ & $305.5 \pm 0.92$ & n.s. & $305.5 \pm 1.83$ & $305.5 \pm 0.61$ & n.s. \\
\hline $\mathrm{IL}-10 / \mathrm{pg} \cdot \mathrm{ml}^{-1}$ & $194.1 \pm 5.24$ & $239.9 \pm 11.9$ & n.s. & $156.1 \pm 1.4$ & $166.8 \pm 0.83$ & n.s. & $150.2 \pm 0.9$ & $159.0 \pm 0.48$ & n.s. \\
$\mathrm{IFN} \gamma / \mathrm{pg} \cdot \mathrm{ml}^{-1}$ & $163.0 \pm 24.5$ & $154.5 \pm 25.9$ & n.s. & $145.5 \pm 1.45$ & $145.5 \pm 0.58$ & n.s. & $145.5 \pm 1.45$ & $160.9 \pm 1.6$ & n.s. \\
$\mathrm{TNF} \alpha / \mathrm{pg} \cdot \mathrm{ml}^{-1}$ & $92.5 \pm 1.02$ & $85.9 \pm 0.6$ & n.s. & $96.7 \pm 1.16$ & $97.9 \pm 2.25$ & n.s. & $97.3 \pm 2.63$ & $85.4 \pm 0.59$ & n.s. \\
\hline
\end{tabular}

${ }^{1}$ Data are means \pm SEM; $\mathrm{ND}=$ not detectable; n.s., no significant change.

Table 8. Modulation by diet of age-related changes in analyte concentrations. Analytes listed are those which showed significant changes with age in animals eating the control diet; the direction of change is indicated. n.s., no significant change.

\begin{tabular}{lll}
\hline Analyte changed in control diet & Change in High Fat diet & Change in HFHS diet \\
\hline Potassium decreased & n.s. & Decreased \\
Iron decreased & n.s. & n.s. \\
Albumin decreased & Decreased & n.s. \\
AST decreased & n.s. & Increased \\
ALT decreased & n.s. & n.s. \\
Total cholesterol increased & n.s. & Increased \\
HDL-cholesterol increased & n.s. & Increased \\
\hline
\end{tabular}

sub-optimal diets there are a number of deviations from this pattern, and in animals eating a HFHS diet, there is also evidence of impairment of kidney function.

Considering first the blood electrolytes, it is notable that although there is a non-significant trend upwards in sodium concentration, there is a significant decrease in potassium with age. Interestingly, although sodium and potassium are regulated together so that a correct electrolyte balance is maintained, low potassium has been linked to high blood pressure, independently of high sodium $[15,16]$. Indeed it has been reported that raising potassium levels by dietary supplementation with potassium alginate can reduce hypertension in rats [17]. The decrease in potassium was not seen in animals eating the HF diet; nor did these rats show any increase in sodium levels. However, animals eating the HFHS diet showed highly significant 
differences in both potassium (decreased) and sodium (increased), indicating that these animals are at increased risk of hypertension. This is in line with findings from a large body of clinical literature [16] and demonstrates the validity of our approach.

Animals eating the control diet also showed a signifycant decrease in serum iron concentration. There is no obvious reason for this, as the dietary supply is adequate and no iron-related health problems were observed. The 12 -month values are comparable to samples from other ages and diets, suggesting that the 3-month samples may be artificially high. Haemolysis of original samples can give rise to high iron and potassium values, and this may partially account for the high potassium levels seen in the three-month-old control animals (see above); however the highly significant decrease with age observed in HFHSfed animals must have an endogenous cause as there was no haemolysis in these samples. Changes in iron metabolism in the context of reactions with reactive oxygen species have been linked to ageing and inflammation [18], and free iron is a risk factor for cardiovascular disease [19] but these reported changes relate to an increase in iron concentration, not a decrease as seen here.

Turning to markers of liver function, animals eating the control diet showed decreases over time in the concentration of albumin, and the activities of AST, ALT, and the AST: ALT ratio. A drop in serum albumin is a marker for malnutrition and inflammation [20], and the observation that a similar drop is also seen in animals eating the HF diet suggests that in this study it may be a marker of nutritional imbalance, particularly since in our study we see no signs of inflammation (see below). However, a decrease in albumin concentration was not seen in animals eating the HFHS diet, which arguably is less nutritionally adequate than the other two diets. The HF animals showed falls in AP and AST: ALT. Low serum alkaline phosphatase has also been associated with malnutrition [21], and the observation that HFHS-fed rats, but not control rats, also exhibit lowered levels supports this. Animals in every group showed changes in AST, ALT and the AST: ALT ratio. Notably, HFHS-fed animals showed a significant increase in AST and in the AST: ALT ratio. Both these changes indicate liver dysfunction, and this is consistent with our previous findings relating to liver dysfunction in animals eating a cafeteria diet [13]. HFHS-fed animals also showed increases in urea and creatinine, suggesting that their kidney function becomes impaired with age.

Dyslipidaemia is associated with an increased risk of occlusive cardiovascular disease. Control animals showed increases in both total and HDL-cholesterol with age. These changes were also seen in HFHS-fed rats, which additionally showed raised serum TG. Interestingly, rats fed the HF diet did not exhibit any significant increases in these parameters.

Somewhat surprisingly, given the wealth of data linking ageing with inflammation [22], we observed no differences in any of the measures of inflammation that we examined. Indeed, levels of CRP were barely detectable, and levels of inflammatory cytokines were uniformly low. It is possible that the inflammatory state associated with ageing is a late-onset phenomenon in the rat, and detectable changes cannot be observed at the ages we studied.

There were some significant differences between the diets in age-related analyte changes. Table 8 shows the analytes whose concentrations or activities changed with age in animals eating the control diet, but in addition to modulating these changes the experimental diets produced additional changes. Alkaline phosphatase activities were elevated, and AST and ALT activities depressed in both experimental diets (Table 5), probably reflecting the metabolic changes previously described [13]. There were relatively few changes shown by the HF animals, and this may reflect the fact that they are eating the control diet, containing the correct nutrients, plus a fat-rich supplement. Changes in these animals are therefore likely to reflect nutritional imbalance rather than deficiency. On the other hand, the HFHS-fed animals ingest a nutritionally undesirable diet that is particularly high in both simple carbohydrates and saturated fats and low in protein. It is therefore not surprising that they exhibit deficiencies in kidney (evidenced by changes in serum urea and creatinine; Table 4) and liver (evidenced by changes in serum AP, AST and ALT; Table 5) function from an early age. These animals also exhibit lower HDL-cholesterol and raised TG, indicating that they are at higher risk of cardiovascular diseases.

In conclusion, we have identified a number of age-related changes in blood analytes that are detectable at an early age, well before any clinical manifestations are evident. These changes can be modulated by diet, and the wide array of changes indicative of dysfunction shown by HFHS-fed animals emphasises the undesirability of such a diet. However, it is notable that in animals eating the HF diet alkaline phosphatase activity is raised, but the 'normal' changes (observed in control animals) in levels of potassium, iron, AST, ALT, total and HDLcholesterol are not seen. This observation suggests that in some circumstances this type of diet may alleviate some age-associated changes.

\section{Acknowledgements}

We thank Drs I. Romero and J. Phillips for helpful comments on the manuscript. Contributions to this work were as follows: HAM planned the experiments, carried out the ELISAs and wrote the paper. WSW and IW carried 
out the biochemical analyses and contributed to the study design and discussion. DAS and KE prepared the diets, tended the animals and obtained the blood samples.

\section{REFERENCES}

[1] N. Goldman, C. M. Turra, D. A. Glei, C. L. Seplaki, Y.-H. Lin and M. Weinstein, "Predicting Mortality from Clinical and Non-Clinical Biomarkers," Journal of Gerontology and Medical Science, Vol. 61, No. 10, 2006, pp. 10701074.

[2] S. N. Meydani and D. Wu, "Age-Associated Inflammatory Changes: Role of Nutritional Intervention," Nutrition Reviews, Vol. 65, No. 2, 2007, pp. S213-S216. doi:10.1301/nr.2007.dec.S213-S216

[3] M. Maggio, J. M. Guralnik, D. L. Longo and L. Ferrucci, "Interleukin 6 in Aging and Chronic Disease: A Magnificent Pathway," Journal of Gerontology and Medical Science, Vol. 61, No. 6, 2006, pp. 575-584.

[4] C. Franceschi, "Inflammaging as a Major Characteristic of Old People: Can It Be Prevented or Cured?" Nutrition Reviews, Vol. 65, No. 12, 2007, pp. S173-S176. doi:10.1301/nr.2007.dec.S173-S176

[5] P. L. McGeer and E. G. McGeer, "Inflammation and the Degenerative Diseases of Aging," Annals of the New York Academy of Science, Vol. 1035, 2004, pp. 104-116. doi:10.1196/annals.1332.007

[6] P. M. Ridker, "Inflammatory Biomarkers and Risks of Myocardial Infarction, Stroke, Diabetes, and Total Mortality: Implications for Longevity," Nutrition Reviews, Vol. 65, No. S3, 2007, pp. S253-S259. doi:10.1301/nr.2007.dec.S253-S259

[7] P. C. Calder, "Fat Chance of Immunomodulation," Immunology Today, Vol. 19, No. 6, 1998, pp. 244-247. doi:10.1016/S0167-5699(98)01264-X

[8] H. A. MacQueen, D. Sadler and C. A. Mattacks, "Dietary Fatty Acids Influence the Appearance of Tumour Necrosis Factor-Alpha? Receptors on Adipocytes Following an Immune Challenge," British Journal of Nutrition, Vol. 84, No. 3, 2000, pp. 387-392.

[9] T. T. Fung, M. L. McCullough, P. K. Newby, J. E. Manson, J. B. Meigs and N. Rigai, "Diet-Quality Scores and Plasma Concentrations of Markers of Inflammation and Endothelial Dysfunction," American Journal of Clinical Nutrition, Vol. 82, No. 1, 2005, pp. 163-173.

[10] R. Takechi, S. Galloway, M. Pallebage-Gamarallage, et al., "Dietary Fats, Cerebrovasculature Integrity and Alzheimer's Disease Risk," Progress in Lipid Research, Vol. 49, No. 2, 2010, pp. 159-170.

[11] K. He, K. Liu, M. L. Daviglus, et al., "Associations of Dietary Long-Chain n-3 Polyunsaturated Fatty Acids and Fish with Biomarkers of Inflammation and Endothelial Activation,"
American Journal of Cardiology, Vol. 103, No. 9, 2009, pp. 1238-1243. doi:10.1016/j.amjcard.2009.01.016

[12] G. Mayot, K. Vidal, L. Combaret, et al., "Presence of Lowgrade Inflammation in Old Rats Does Not Worsen Skeletal Muscle Loss under an Endotoxaemic and Dietary Stress," Experimental Gerontology, Vol. 42, No. 12, 2007, pp. 1167-1175. doi:10.1016/j.exger.2007.09.002

[13] H. A. MacQueen, D. A. Sadler, S. Moore, et al., "Deleterious Effects of a Cafeteria Diet on the Livers of NonObese Rats," Nutrition Research, Vol. 27, No. 1, 2007, pp. 38-47. doi:10.1016/j.nutres.2006.10.003

[14] R. Mead, "The Design of Experiments," Cambridge University Press, Cambridge, quoted in M. F. W. Festing, P. Overend, R. Gaines Das, M. Cortina Borja and M. Berdoy, "The Design of Animal Experiments," Royal Society of Medicine Press, London, 2002.

[15] K. T. Khaw and E. Barrett-Connor, "Dietary Potassium and Stroke-Associated Mortality. A 12-Year Prospective Population Study," New England Journal of Medicine, Vol. 316, No. 5, 1987, pp. 235-240. doi:10.1056/NEJM198701293160502

[16] H. J. Adrogue and N. E. Madias, "Sodium and Potassium in the Pathogenesis of Hypertension," New England Journal of Medicine, Vol. 356, No. 19, 2007, pp. 1966-1978. doi:10.1056/NEJMra064486

[17] Y. Y. Chen, W. Ji, J.-R. Du, et al., "Preventive Effects of Low Molecular Mass Potassium Alginate Extracted from Brown Algae on DOCA Salt-Induced Hypertension in Rats," Biomedical Pharmacotherapy, Vol. 64, No. 4, 2010, pp. 291-295. doi:10.1016/j.biopha.2009.09.004

[18] D. B. Kell, "Iron Behaving Badly: Inappropriate Iron Chelation as a Major Contributor to the Aetiology of Vascular and Other Progressive Inflammatory and Degenerative Diseases," BMC Medical Genomics, Vol. 2, No. 1, 2009, pp. 63-82. doi:10.1186/1755-8794-2-2

[19] S. Richer, D. Rudy, L. Statkute, K. Karofty and J. Frankowski, "Serum Iron, Transferrin Saturation, Ferritin, and Dietary Data in Age-Related Macular Degeneration," American Journal of Therapeutics, Vol. 9, No. 1, 2002, pp. $25-$ 28. doi:10.1097/00045391-200201000-00006

[20] B. R. Don and G. Kaysen, "Serum Albumin: Relationship to Inflammation and Nutrition," Seminars in Dialysis, Vol. 17, No. 6, 2004, pp. 432-437. doi:10.1111/j.0894-0959.2004.17603.x

[21] G. Lum, "Significance of Low Serum Alkaline Phosphatase Activity in a Predominantly Adult Male Population," Clinical Chemistry, Vol. 41, No. 4, 1995, pp. 515518.

[22] D. Wu and S. N. Meydai, "Age-Associated Changes in Immune and Inflammatory Responses: Impact of Vitamin E Intervention," Journal of Leukocyte Biology, Vol. 84, No. 4, 2008, pp. 900-914. doi:10.1189/jlb.0108023 